This is a self-archived - parallel published version of this article in the publication archive of the University of Vaasa. It might differ from the original.

\title{
Differences in horizontally individualist and vertically collectivist consumers' environmental behaviour: a regulatory focus perspective
}

\author{
Author(s): Rahman, Saleem ur \\ Title: Differences in horizontally individualist and vertically collectivist \\ consumers' environmental behaviour: a regulatory focus perspective \\ Year: $\quad 2019$ \\ Version: Accepted manuscript \\ Copyright (C) 2019 Inderscience Enterprises Ltd.
}

Please cite the original version:

Rahman, S. (2019). Differences in horizontally individualist and vertically collectivist consumers' environmental behaviour: a regulatory focus perspective. International Journal of Business and Emerging Markets (IJBEM), 11(1), 73-88.

https://dx.doi.org/10.1504/IJBEM.2019.097479 


\title{
Differences in horizontally individualist and vertically collectivist consumers' environmental behavior: A regulatory focus perspective
}

Saleem ur Rahman

saleem.rahman@uva.fi

School of Marketing and Communication, University of Vaasa, Wolffintie 34, FI-65200 Vaasa, Finland

\begin{abstract}
Building on horizontal and vertical individualism and collectivism (HV I-C) typology and regulatory focus theory (RFT), this study aims to examine cross-cultural environmental behaviour differences between HI-Finnish and VC-Pakistani consumers. In regards to consumers' attitude towards environmentally friendly products, the results demonstrated predominantly HI-promotion-focused regulatory fit effect in Finland and VC-preventionfocused regulatory fit effect in Pakistan. Consequently, consumers' environmentally friendly products' attitude positively affect their purchase intentions. This study contributes to the sustainability literature by examining the overlooked appropriateness of RFT and HV I-C in cross-cultural environmental behaviour. Managers can use the insights of this study to market their environmentally friendly products more effectively across different cultures.
\end{abstract}

Keywords environmentally friendly products, consumers, regulatory focus, cross-cultural, horizontal individualism vs vertical collectivism 


\section{Introduction}

When a consumer decides to buy a product or service, there is always potential for that decision to be part of a sustainable or unsustainable pattern of consumption. Their purchase decisions may prevent or promote environmental degradation. While consumers may be willing to take responsibility for the environmental impact of their purchases, greening their consumption patterns is not easy (Quazi, Amran and Nejati, 2016; Fowler and Close, 2012). It seems that, regardless of consumers' concerns, they continue to buy hazardous non-green products. Researchers have consistently struggled to accurately predict possible antecedents of consumers' pro-environmental behaviour (Cho, Thyroff, Rapert, Park and Lee, 2013) and the motives behind consumers' environmental or sustainable consumption are still unclear (Zagata, 2014).

Marketing researchers argue that consumer behaviour is goal-orientated and consumers' purchase decisions are the expressions of those goals (Higgins, 1997). For example, eastern and western cultures that are classified as collectivistic and individualistic (Hofstede, 1980) are described as prevention- and promotion-focused, respectively (Higgins, Pierro and Kruglanski, 2008). However, the structures of cultures are changing and as a result, consumer behaviour varies across different cultures. Consequently, individuals regulate their goals in different ways (Higgins, 1997; Ouschan et al., 2007; Lee et al., 2000; Shavitt, Lee and Torelli, 2009; Poels and Dewitte, 2008).

Researchers have mainly relied on using regulatory focus theory (RFT) to examine how consumers' regulate their goal orientations in a given situation. RFT is devoted to the pursuit of pleasure goals, i.e., promotion focused, and the avoidance of pain goals, i.e., prevention focused (Higgins, 2012; Higgins, 1997). The role of RFT is also evident in the research on consumers' environmentally friendly consumption (Onwezen, Bartels and Antonides, 2014; Hsu and Chen, 2014; Miniero et al., 2014; Pula, Parks and Ross, 2014; Kareklas, Carlson and 
Muehling, 2012; Bhatnagar and McKay-Nesbitt, 2016; Chen, Lee and Huang, 2015). However, the findings of these studies are limited to basing consumers' sustainable consumption goals as pro-self or pro-others, construing them as independent and interdependent selves (Markus and Kitayama, 1991; Kareklas et al., 2012; Chen et al., 2015) or individualists and collectivists (IND/COL) (Hofstede, 1980; Onwezen et al., 2014). Research reveals that consumers face a trade-off between their individual and collective interests when behaving in environmentally friendly ways (Moisander, 2007; Gupta and Ogden, 2009; Van Lange et al., 2013) and that their promotion- and prevention-focused orientations may transcend each other in the context of environmentally friendly behaviour across different cultures (Bhatangar and McKayNesbitt, 2016; Chen, Lee and Huang, 2015).

As no consumers are alike, such as that consumers' goals and cultural characteristics are not homogenous, the purpose of this study is to blend RFT with HV I-C typology (Triandis and Gelfand, 1998), so as to provide important findings in advancing cross-cultural sustainable consumption research that demonstrates whether consumers' prevention and promotion focus orientations have any impact on environmentally friendly behaviour. Here, the authors infer that environmental behaviour is not limited to individualistic or collectivistic interests of consumers, but the interplay of RFT can be useful with horizontal and vertical individualism and collectivism (HV I-C) typology, which is more comprehensive (Triandis and Gelfand, 1998). This study offers several managerial and marketing implications that may be essential for national as well as international producers, marketers and policymakers. In the remainder of the study, the literature review, theoretical framework, research method, findings and results, discussion and conclusions are discussed. Managerial implications, limitations and future research recommendations are also considered at the end. 


\subsection{Literature review}

\section{$1.1 \quad$ Regulatory focus theory}

The primary basis for this research is Regulatory focus theory (RFT). RFT suggests that individuals have two different motivational preferences for the means to achieve goals: promotion-focused and prevention-focused (Higgins, 1997). Promotion orientated individuals focus on achieving an ideal state, are sensitive to gains and strive eagerly to reach goals. Individuals with a prevention orientation focus on pursuing goals cautiously, preventing problems and are sensitive to losses (Shah, Higgins and Friedman, 1998). Individuals feel more satisfied when regulatory fit occurs and matches with their goals (Kruglanski, 2006). Lee and Aaker (2004) found that regulatory fit leads to positive attitudes, which improve individuals' behaviour. Consumers evaluate the purchases they make based on these orientations and consider whether the result will maximize their benefits or minimize negative outcomes (Aaker and Lee, 2006). Consequently, they pay more for a product if it matches their promotion- or prevention-focused orientation (Avent and Higgins, 2006). Due to its importance in people's decision-making, RFT has been widely used in the majority of studies, including those on consumers' responses to advertising (Aaker and Lee, 2001; Chowdhury, Micu, Ratneswar and Kim, 2015), health-relevant behaviours (Haught, Rose and Brown, 2015), safety behaviour (Aryee and Hsiung, 2016), restaurant choice (Pham and Chang, 2010) word of mouth communications (Pentina, Bailey and Zhang, 2015) and food consumption (Pula, Parks and Ross, 2014). RFT is appropriate for many consumers' decisions and remains one of the stable individual difference variables in consumer behaviour (Higgins, 2012).

\subsection{Horizontal vs Vertical individualism and collectivism (HV I-C)}

HV I-C addresses the equality/inequality belief among members of a cultural group (Singelis et al., 1995; Triandis and Gelfand, 1998; Shavitt et al., 2006; Shavitt and Cho, 2016). For instance, vertical individualistic (VI) individuals are from France, Great Britain and the United 
States, with characteristics focused on hierarchy, power, individual competition and the value of being different and important. Individuals from India, Japan and Korea are vertical collectivistic (VC) in nature, emphasizing submission and compliance with authority, prioritizing group benefits, goals and interests and preserving unity. Citizens of Denmark, Norway, Sweden and Australia are horizontal individualistic (HI) and bear the characteristics of equality, independence, self-reliance and uniqueness. Horizontal collectivistic (HC) people are from Israeli kibbutzim, emphasizing equity, sociability, interdependence and group commonality. These characteristics bring out different themes and each of them can be displayed by individuals within any culture (Komarraju and Cokley, 2008). The role of HV I$\mathrm{C}$ dimensions has been widely examined in different research contexts; among these, its role in consumer psychology is most prominent. For example, consumers with VI (high on competitiveness) orientations are brand conscious and status orientated and do not tolerate lying (Lu et al., 2011; Zhang and Nelson, 2016). VC (high on group dependence) orientated consumers are normative, pro-environmental and prone to other directed symbolism and nomophobia (Yi-Cheon Yim et al., 2014; Shukla, Singh and Banerjee, 2015; Arpaci, 2017; Waylen et al., 2012). Individuals rated high on HI (high on uniqueness) achieve outcomes with competence, display impersonal interests in nutritional practices for society, show proenvironmental attitudes and are satisfied with their lives (Sandhu and Ching, 2014; Torres and Perez-Nebra, 2007; Cho et al., 2013; Parker and Grinter, 2014). HC individuals (high on interdependence) show positive environmental attitudes, are interested in cause-related marketing, give preference to products for religious reasons and show leisure attitudes (Cho et al., 2013; Wang, 2014; Jamal and Sharifuddin, 2015; Wong, Newton and Newton, 2014). 


\subsection{Hypotheses development}

\subsection{Horizontal individualism vs vertical collectivism differences in regulatory focus}

Earlier research has argued that consumers' regulatory goals, attitudes and behaviour can be distinctively different in different cultures (Higgins, 1997). Researchers assumed that consumers in individualistic cultures would be promotion-orientated and consumers from collectivistic cultures would be prevention-orientated (Chen, Ng and Rao, 2005; Lee et al., 2000). However, it is not true. From the review of literature, it seems that earlier research was unable to produce credible evidence on how and why regulatory fit effect occurs in different contexts, thus compelling the authors to understand regulatory fit occurrence in cross-cultural contexts. One possible explanation is that regulatory focus orientations are not fixed (Miniero et al., 2014) and different across different cultural contexts (Bu, Kim and Son, 2013).

Since the countries of investigation in this study are Finland and Pakistan, the authors argue that the goals of consumers in Finland are promotion-focused to achieve gains and will be compatible with their horizontal individualist characteristics. On the contrary, Pakistani consumers are prevention-focused to avoid losses and will be compatible with their vertical collectivistic characteristics. For instance, earlier research supports our selection of these countries. Finns represents HI specific cultural characteristics such as uniqueness, independence, self-reliance and equality (Khatri, Tsang, and Begley, 2005). Finns show positive attitude to products with promoting health claims and experience emotions having positive outcomes (Grunert et al, 2009; Loumala, Kumar, Singh, and Jaakkola, 2015), whereas the characteristics of Pakistanis are relatively obligatory, show status or power distance, group orientation, and hierarchy (Sivadas, Bruvold, and Nelson, 2008), which shows their VC cultural orientations (Imam, 2013). Moreover, Pakistanis have also been characterized as prevention 
focused consumers (Ashraf, Razzaque, and Thongpapani, 2016). Therefore, it is hypothesized that,

H1a. There is a positive influence of HI on consumers' promotion-focused orientations but (H1b) a negative influence, or no influence, on their prevention focus in Finland;

H2a. There is a positive influence of VC on consumers' prevention-focused orientations but (H2b) a negative effect, or no effect, on their promotion-focused orientations in Pakistan;

\subsection{Regulatory focus difference in environmental attitude and purchase}

\section{intentions}

RFT also appears in research on predicting consumers' pro-environmental behaviours, but with mixed results. For instance, prevention-orientated consumers feel a moral duty to adopt green lifestyles and prefer natural contents in food (Miniero et al., 2014; Pula, Parks and Ross, 2014). Conversely, promotion goals were found to be more dominant than prevention goals in environmentally responsible behaviour and the purchase of organic food (Chen, Lee, Huang, 2015). Bhatnagar and McKay-Nesbitt (2016) found that promotion- and prevention-focused individuals respond similarly to recycling. In their study, Onwezen et al. (2014) found no difference regarding self-regulated anticipated pride and guilt in the purchase intentions of consumers from individualistic and collectivistic countries. According to Kareklas et al. (2012), promotion-orientated environmental appeals were found to be more effective than prevention-orientated environmental appeals for consumers with interdependent self-views. On the contrary, it has been suggested that consumers perceive prevention-focused appeals better than promotion-focused appeals when marketers position sustainable products (Bullard and Manchanda, 2013).

Since, pro-environmental behaviour is described as "behaviour that consciously seeks to minimize the negative impact of one's actions on the natural and built world" (Kollmuss and Agyeman, 2002). Therefore, instead of assuming consumers' environmental goals are 
independent or interdependent and/or individualistic or collectivistic (McCarty and Shrum, 2001; Soyez, 2012; Park et al, 2007), it is possible that there may be a difference in consumers' regulatory focus and environmental behaviour in countries structured as horizontal and vertical or collectivist and individualist (Cho et al., 2013; Waylen et al., 2012). For example, in their green purchasing behaviour, there is a difference in consumers' underlying emotional mechanisms between attitude-intention associations in individualistic versus collectivistic cultures (Onwezen et al., 2014). Therefore, it can be possible that a pro-environmental consumer may activate his or her prevention- or promotion-focused orientation despite his or her chronic regulatory focus orientation as an individualist or a collectivist (Higgins, 2002). Consequently, we argue that, instead of assuming congruency between IND/COL and regulatory focus emotions, it is possible that the formation of regulatory fit effect will prevail in $\mathrm{HI}$ and $\mathrm{VC}$ cultures and produce cultural indigenous consumers' environmentally friendly attitude and purchase intentions. Therefore, it is hypothesized that,

H1c. Promotion-focused orientations positively influence but (H1d) prevention-focused orientations have a negative influence, or no influence, on consumers' attitude in Finland;

H1e. Consumers' attitude positively influence consumers' purchase intentions in Finland;

H2c. Prevention-focused orientations positively influence but (H2d) promotion-focused orientations have a negative influence, or no influence, on consumers' attitude in Pakistan; and

H2e. Consumers' attitude positively influence consumers' purchase intentions in Pakistan.

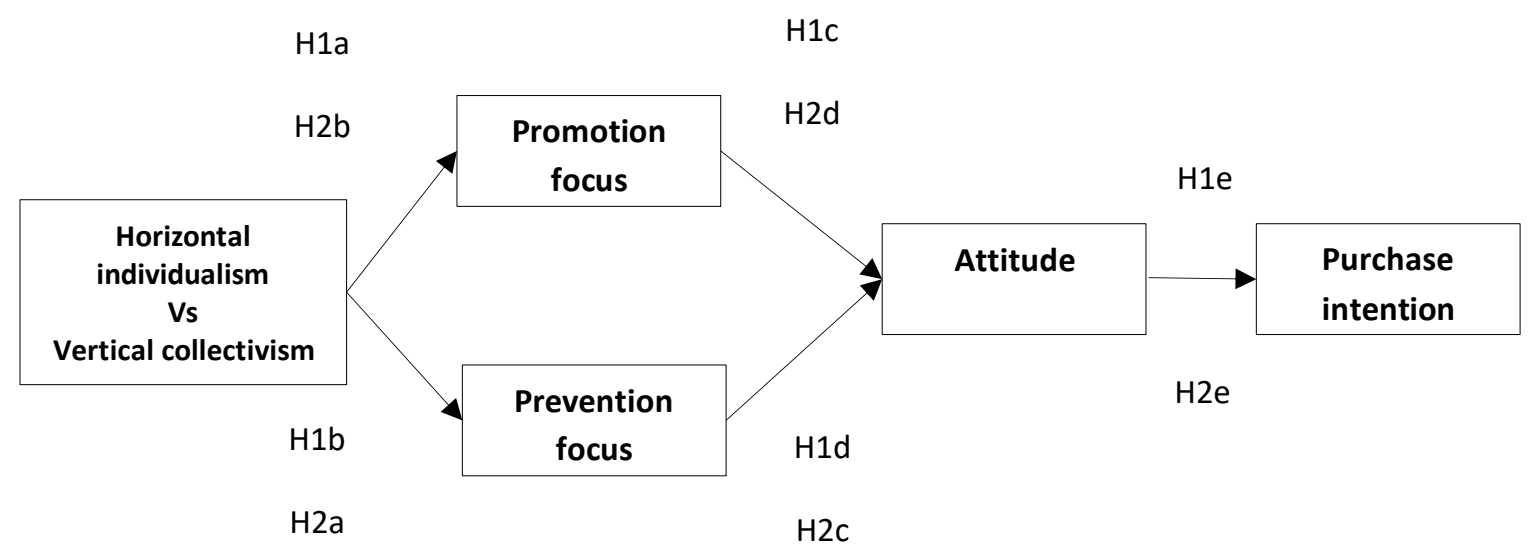


Fig 1.0 Conceptual framework

\subsection{Methodology}

\subsection{Data collection and sample}

The study sample includes people belonging to two countries: Finland and Pakistan. The authors adopted non-probability convenient sampling techniques for data collection. The respondents were contacted in malls, parks, city centres, universities and public places. Data were received from 179 Pakistani respondents residing in Rawalpindi and Islamabad during the months of August to October 2017 and from 207 Finnish respondents residing in Vaasa and Helsinki from May to July 2017.

\subsection{Measures}

The study questionnaire consisted of two parts. To avoid the confusion of respondents in understanding the questions, the questionnaire was translated into the native languages of Pakistan-Urdu and Finland-Finnish. The first part included scale items of independent and dependent variables and the second part included questions about demographic characteristics, such as age, gender, marital status, education and income level of the respondents. Scale items of horizontal individualism (HI) and four items of vertical collectivism (VC) value orientations were adopted from the study of Triandis and Gelfand (1998) and were measured using a Likert scale of "Strongly disagree" (1) to "Strongly

agree" (5). Statements on regulatory focus orientations were adopted from the study of Higgins et al. (2001) and measured as advised by that author. Scale items on consumers' environmental attitude variable were adopted from the study of Mostafa (2007) and were measured using a 1-5 Likert scale. Questionnaire items on purchase intention variables were taken from the study of Paul, Modi and Patel (2016) and were measured using a Likert scale of "Strongly disagree" (1) to "Strongly agree" (5).

\subsection{Data analysis tests}


The collected data were analysed using the statistical application software Statistical Program for Social Scientists (SPSS 20.0). Moreover, to test the fitness of the model, the authors applied a structural equation modelling (SEM) technique using SmartPLS (v. 3.2.6) application software.

\subsection{Results and findings}

\subsection{Sample characteristics}

The demographic information shows that the majority of the respondents were aged 21-25 in both samples (Pakistan, 35, 19.5\%; Finland, 51, 24.6\%). However, there were more females in the Finnish sample $(154,74.4 \%)$ than in the Pakistani sample $(80,44.7 \%)$. There were six (3.4\%) respondents with doctorate degrees in the Pakistani sample but only one $(0.6 \%)$ in the Finnish sample. The majority $(39,21.8 \%)$ of the respondents in the Pakistani sample had income levels Pakistani rupees (PKR) between 30,001 to 35,000, while in the Finnish sample $52(25.1 \%)$ and $37(17.9 \%)$ respondents had income levels of 501-999 and 2,000-2,499, respectively.

\subsection{Discriminant validity}

The Pearson correlation test of statistics was used to view the interrelationship between the variables. For evaluating the reliability and convergent validity, the authors computed composite reliability (CR) and average variance extracted (AVE). In addition, the square root of AVEs was computed to check the adequate discriminant validity that exceeds correlation coefficients between the pair of corresponding constructs (See Table 1.0 and 2.0).

Table 1.0 Discriminant validity (Finland)

\begin{tabular}{|c|c|c|c|c|c|c|c|}
\hline Variables & HI & Pro & Pre & EA & PI & $\mathbf{C R}$ & AVE \\
\hline HI & (0.79) & & & & & 0.757 & 0.626 \\
\hline Pro & $.387^{* *}$ & (0.78) & & & & 0.819 & 0.601 \\
\hline
\end{tabular}




\begin{tabular}{|l|l|l|l|l|l|l|l|}
\hline Pre & -.036 & .012 & $\mathbf{( 0 . 8 3 )}$ & & & 0.871 & 0.692 \\
\hline EA & $.260^{* *}$ & $.228^{* *}$ & $-.137^{*}$ & $\mathbf{( 0 . 7 8 )}$ & & 0.887 & 0.612 \\
\hline PI & $.160^{*}$ & $.147^{*}$ & -.078 & $.727^{* *}$ & $\mathbf{( 0 . 8 8 )}$ & 0.930 & 0.770 \\
\hline
\end{tabular}

Table 2.0 Discriminant validity (Pakistan)

\begin{tabular}{|c|c|c|c|c|c|c|c|}
\hline Variables & $\mathrm{VC}$ & Pro & Pre & $\mathbf{E A}$ & PI & CR & AVE \\
\hline $\mathrm{VC}$ & $(0.86)$ & & & & & 0.852 & 0.743 \\
\hline Pro & .085 & $(0.79)$ & & & & 0.776 & 0.636 \\
\hline Pre & $.360^{* *}$ & .100 & $(0.79)$ & & & 0.839 & 0.636 \\
\hline EA & $.444^{* *}$ & .137 & $.577^{* *}$ & $(0.75)$ & & 0.796 & 0.567 \\
\hline PI & $.273^{* *}$ & $.194^{* *}$ & $.499^{* *}$ & $.443^{* *}$ & $(0.80)$ & 0.842 & 0.640 \\
\hline
\end{tabular}

Notes: Values of square root of AVEs are shown diagonally in parentheses.

**. Correlation is significant at the 0.01 level (2-tailed)

*. Correlation is significant at the 0.05 level (2-tailed)

\subsection{Structural Equation Modelling (SEM) Analysis}

To test the relationship in the research model as specified during the conceptualization stage, the authors used a SEM approach (Diamantopoulos et al., 2000). Hair et al. (2006) argue that SEM is a collection of statistical models that helps researchers simultaneously examine the interrelationship between different variables. Therefore, to analyse the data and check the hypothesized relationship of the model, the authors employed partial least squares (PLS) SmartPLS software. PLS is prediction-orientated SEM-based software that is convenient and works well with smaller data sets (Henseler, Ringle and Sinkovics, 2009). A two-step SEM analysis approach was performed on the data (Anderson and Gerbing, 1999).

\subsection{Measurement model}

There are five latent variables in each model of the two samples that employ the reflective measurement model on each of the different items of the scale. Loadings of all the factors 
showed adequate convergent validity, which indicates acceptable internal consistency above the recommended value of 0.50 (Fornell and Larcker, 1981) (see Figures 1 and 2).

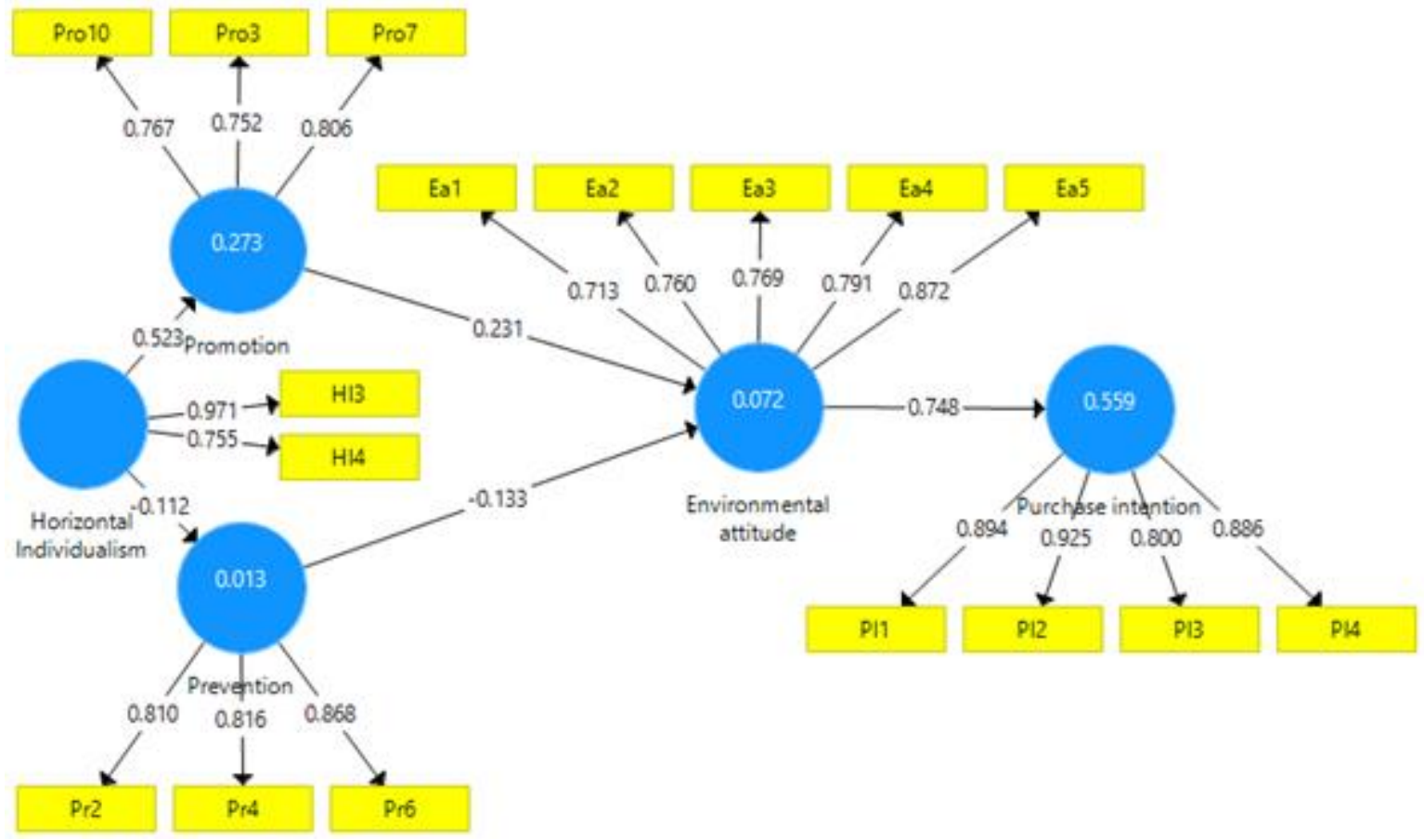

Fig 2.0 Measurement model (Finland)

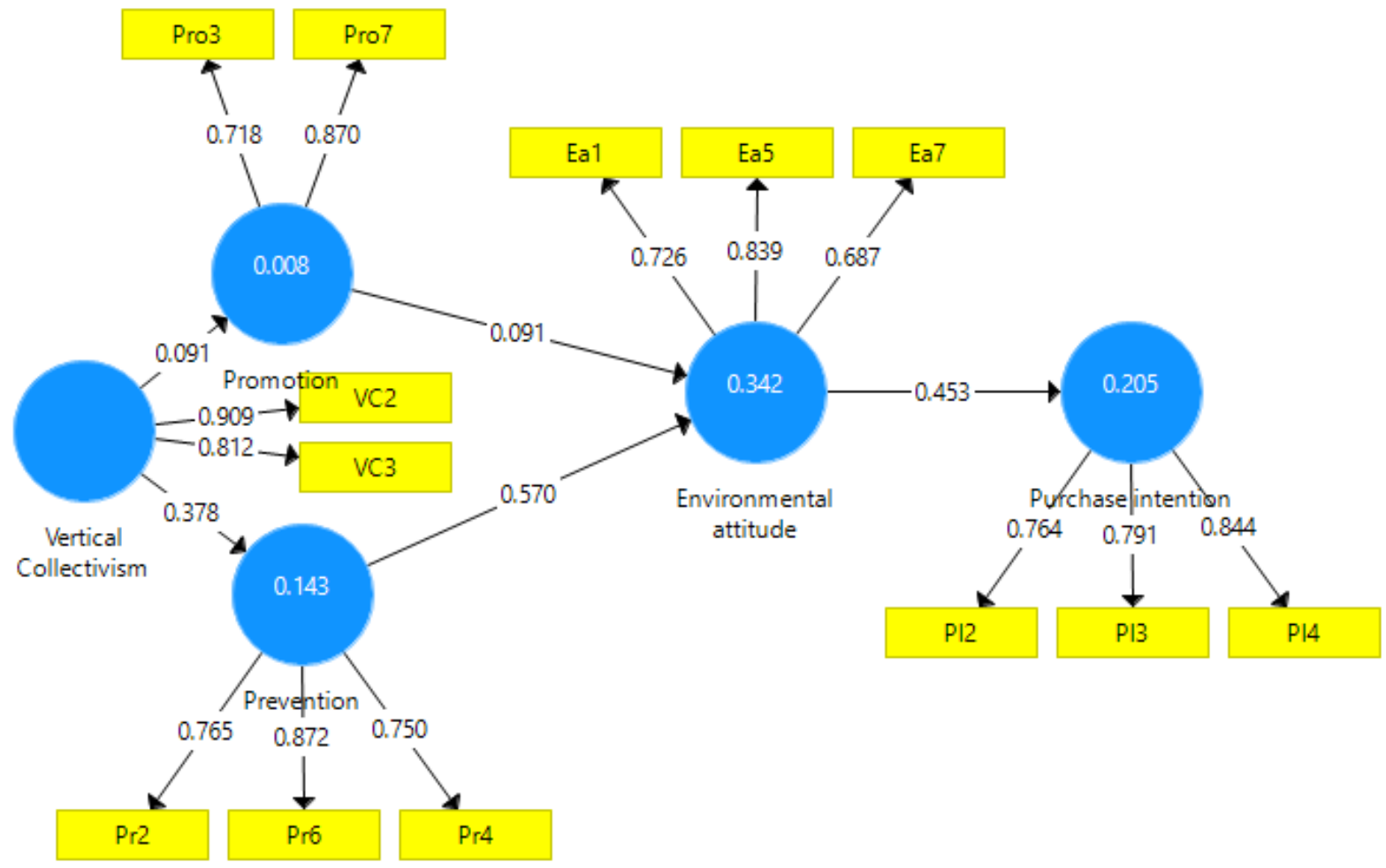

Fig 3.0 Measurement model (Pakistan)

\subsection{Structural model estimation hypotheses result}


The first step in structural model estimation processes is to calculate the value of $\mathrm{R}^{2}$, which shows the amount of variance in a dependent variable by independent variables. In the current model, the value of $\mathrm{R}^{2}$ for Finland was 0.55 and for Pakistan was 0.20 , which demonstrates considerable significance for the interpretation of the variance. After this step, the crossvalidated redundancy measures, called $\mathrm{Q}^{2}$, were calculated using blindfolding command in PLS and resulted in values of 0.39 for Finland and 0.23 for Pakistan. In the next step, to estimate the accuracy of the measurement model, calculate the path coefficients and generate t-values, the authors ran a bootstrapping method for sampling test (Roldan and Sanchez-Franco, 2012). The path coefficients showed the strength of the relationship between the independent and dependent variables of the model. The hypotheses of this study were examined using the path coefficients. The data in the first model of Finland accounted for $55 \%$ of the variance in the dependent variable. Regarding the first hypothesis result, the data demonstrate that horizontal individualism positively influences consumers' promotion-focused orientations $(\beta=0.523, p$ $<0.05)$. Therefore, H1a is accepted. Regarding the influence of HI on prevention focus $(\beta=$ $1.112, p>0.05) \mathrm{H} 1 \mathrm{~b}$ is also accepted because the effect was insignificant. The influence of promotion focus on environmental attitudes was found positive $(\beta=0.231, \mathrm{p}<0.05)$ so $\mathrm{H} 1 \mathrm{c}$ is accepted. The influence of prevention focus on consumers' environmental attitudes was negative $(\beta=-0.133, p>0.05)$. Therefore, H1d is also accepted. Last, the influence of environmental attitudes on purchase intentions was found positive $(\beta=0.748, \mathrm{p}<0.05)$, so H1e is accepted.

The data in the second model of Pakistan accounted for $20 \%$ of variance in the dependent variable. The results demonstrate that vertical collectivism has insignificant influence on consumers' promotion-focused orientations $(\beta=0.091, \mathrm{p}>0.05)$, resulting in an acceptance of $\mathrm{H} 2 \mathrm{a}$, but positively influences prevention-focus orientations $(\beta=0.378, \mathrm{p}<0.05)$, so $\mathrm{H} 2 \mathrm{~b}$ cannot be accepted. The authors accept $\mathrm{H} 2 \mathrm{c}$ because the influence of prevention-focused 
orientations on environmental attitudes was positive $(\beta=0.570, p<0.05)$. The influence of promotion-focused orientation on environmental attitudes was found to be insignificant $(\beta=$ 0.091, $\mathrm{p}>0.05$ ), so $\mathrm{H} 2 \mathrm{~d}$ is also accepted. Last, the authors found that there was a positive influence of environmental attitudes on purchase intentions, thus leading to an acceptance of H2e $(\beta=0.453, p<0.05)$ (see Tables 3 and 4$)$.

Table 3.0 Hypotheses result

Hypotheses Hypothesized path B t-value P-value Label

\begin{tabular}{cccccc}
\hline & & \multicolumn{2}{c}{ Finland } & & \\
\hline H1a & HI $\rightarrow$ Pro & 0.523 & 8.689 & 0.000 & Accept \\
H1b & HI $\rightarrow$ Pre & -0.112 & 1.246 & 0.215 & Accept \\
H1c & Pro $\rightarrow$ EAt & 0.231 & 3.179 & 0.001 & Accept \\
H1d & Pre $\rightarrow$ EAt & -0.133 & 1.646 & 0.100 & Accept \\
H1e & EAt $\rightarrow$ PI & 0.748 & 23.132 & 0.000 & Accept \\
\hline H2a & VC $\rightarrow$ Pre & Pakistan & & \\
H2b & VC $\rightarrow$ Pro & 0.378 & 5.257 & 0.000 & Accept \\
H2c & Pre $\rightarrow$ EAt & 0.091 & 1.078 & 0.281 & Accept \\
H2d & Pro $\rightarrow$ EAt & 0.570 & 8.946 & 0.000 & Accept \\
H2e & EAt $\rightarrow$ PI & 0.091 & 1.240 & 0.251 & Accept \\
Finland $\left(\mathbf{R}^{2}=\right.$ & $\left.0.55, \mathbf{Q}^{2}=0.39\right)$ & & & & \\
\hline
\end{tabular}




\subsection{Discussion}

This study examines the regulatory focus perspectives of consumers on their environmental products' attitude and purchase intentions, comparing two countries based on horizontal and vertical IND/COL cultural differences. It was conceptualized that consumers from a horizontal individualistic culture country (Finland) would be promotion-focused, while consumers from a vertical collectivistic culture country (Pakistan) would be prevention-focused; consequently, the regulatory focus orientations of consumers in the selected countries would affect their environmental products' attitude. The authors were able to find significant research evidence relating RFT to attitudes and purchase intentions in cross-cultural contexts, which is uniquely different from related research on the topic (Kareklas et al., 2012; Chen et al., 2015; Onwezen et al., 2014). In the context of environmental choices, previous research has divided consumers into pro-self and pro-others (interdependent versus dependent selves) or into individualists and collectivists, thus assuming their environmentally friendly choices are different. In general, the present analysis contributes to earlier research about how RFT can be different across cultures (Higgins, 1997; Shavitt, et al., 2006; Poels and Dewitte, 2008), specifically in horizontal individualistic and vertical collectivistic countries (Cho et al., 2013; Waylen et al., 2012). This research improves existing research on the compatibility of RFT in such cultures in terms of environmental behaviour. To date, no research has been conducted on examining the influence of HI vs VC on RFT and consequently on environmental behaviour in cross-cultural context, therefore; our study is the first to examine this relationship. The authors were able to reveal interesting findings. For instance, since consumers in HI cultures are low power distance societies and categorized by characteristics such as equality, uniqueness and self-reliance, the results of this study clearly show that they are promotion focused. It means that HI or Finnish consumers are promotion-focused and their characteristics align when consumers choose environmentally friendly products. On the other hand, when buying environmentally friendly 
products, the main goals of VC or Pakistani consumers are prevention-focused, which are compatible with VC cultural values. In other words, HI consumers may buy environmentally friendly products to achieve gains including health and an ideal state of mind, satisfaction and hedonism, therefore; hoping that their purchases for such gains will make a difference in achieving environmental protection. Consequently, the features of environmentally friendly products match their promotion-focused orientations and HI cultural values. On the contrary, VC orientated consumers are sensitive to losses, so they may buy environmentally friendly products to stop further losses to the environment, prevent pollution and save themselves and their families from the problems created by environmental degradation. This study has helped in identifying the most important elements of environmental behaivor in cross-cultural context. For instance, HI vs VC and RFT interplay will not only change the way we see green buying behaviour of consumers in the two countries, but also motivate companies to produce environmental friendly products to improve their brand image, competitive advantage, and increase overall business performance.

\subsection{Managerial implications}

Several managerial implications and insights can emerge from the findings of the present study, which demonstrates that the success of marketers in cross-cultural contexts depends on their ability to satisfy the value-based needs and motives of consumers who experience regulatory fit in Finland and Pakistan. For instance, a consumer in an HI culture may buy a green product for health, social and ethical reasons, while a consumer in a VC culture may buy the same product for group benefits, such as regulating their health and that of their family, or for the purpose of being respected by others. In this regard, in HI markets such as Finland, there may be high demand for products that are low in calories, of good quality and nutritious, such as food and beverages, organic clothes and organic reusable apparel, toxic and chemical free products such as utensils, colour and paints, and the products that gives benefits when buying 
to farmers, agriculture, humans and animals. In VC cultures such as the Pakistani market, products such as organic beauty and fashion products, eco-friendly transport and cars, organic dishwashing liquid and green white goods can be marketed well. Regulatory focus plays an important role in consumers' environmentally friendly choices in the selected countries. Therefore, companies should pay attention to create products and services identical to their culture-goal fit. Brands carry different meanings and companies can identify the most viable consumer base for their products and services. For example, a positive consumer response will be generated in HI cultures when consumers are exposed to advertisements such as promotions to gain healthy bodies and lifestyles, discourage unhealthy habits and communicate the positive impact of environmentally friendly products on the earth, people, the environment and animals. On the contrary, the following advertisements may be effective in VC culture countries: those that portray environmentally friendly messages such as benefits to families and groups, those displaying the advantages of environmentally friendly products, e.g., how they prevent environmental degradation and atmospheric pollution and are less damaging than conventional products, and those that enhance consumers' social image in society or in groups. We conclude that, the findings of this study are novel and unique for marketers of environmentally friendly products to capitalize their marketing and advertising strategies in $\mathrm{HI}$ and VC cultures.

\subsection{Limitations and future research}

Like other research studies, the current study is not immune from some limitations. First, this study was conducted in only one HI and one VC cultural country context. Therefore, it would be valuable to examine whether the findings are generalizable in other countries and across different cultural contexts. Second, in the context of environmentally friendly choices, the RFT scores clearly indicated the regulatory focus characteristics of the selected HI versus VC cultures. The results may vary and indicate different findings if and when regulatory focus conditions are manipulated and construed for other products and behavioural intentions, so 
future studies should examine this. Third, there can be moderating effects of some factors such as consumers' demographics or other external factors on the relationship between culture, regulatory focus and environmental attitudes. Thus, future studies might examine the role of such factors. Fourth, the sample size in both countries was small and may prevent researchers from generalizing the findings on an overall population. Last, the interplay of RFT can be examined in horizontal collectivistic and vertical individualistic cultures when predicting environmental behaviour of consumers to see if it is suitable. 


\section{References}

1. Aaker, J.L. and Lee, A.Y., 2006. Understanding regulatory fit. Journal of Marketing Research, 43(1), pp.15-19.

2. Anderson, J. C. and D. W. Gerbing: (1988), "Structural Equation Modeling in Practice: A Review and Recommended Two-Step Approach", Psychological Bulletin, Vol. 103, pp. 411-423.

3. Arpaci, I., 2017. Culture and nomophobia: The role of vertical versus horizontal collectivism in predicting nomophobia. Information Development, p.0266666917730119.

4. Aryee, S. and Hsiung, H.H., 2016. Regulatory focus and safety outcomes: An examination of the mediating influence of safety behaviour. Safety science, 86, pp.2735.

5. Ashraf, A.R., Razzaque, M.A. and Thongpapanl, N.T., 2016. The role of customer regulatory orientation and fit in online shopping across cultural contexts. Journal of Business Research, 69(12), pp.6040-6047.

6. Avnet, T., \& Higgins, E. T. (2006). How Regulatory Fit Affects Value in Consumer Choices and Opinions. Journal of Marketing Research, 1-10.

7. Bhatnagar, N. and McKay-Nesbitt, J., 2016. Pro-environment advertising messages: the role of regulatory focus. International Journal of Advertising, 35(1), pp.4-22.

8. Bian, Q. and Forsythe, S., 2012. Purchase intention for luxury brands: A cross cultural comparison. Journal of Business Research, 65(10), pp.1443-1451.

9. Bu, K., Kim, D. and Son, J., 2013. Is the culture-emotion fit always important? Selfregulatory emotions in ethnic food consumption. Journal of Business Research, 66(8), pp.983-988. 
10. Chen, H., Ng, S. and Rao, A.R., 2005. Cultural differences in consumer impatience. Journal of Marketing Research, 42(3), pp.291-301.

11. Chen, N.H., Lee, C.H. and Huang, C.T., 2015. Why buy organic rice? Genetic algorithm-based fuzzy association mining rules for means-end chain data. International journal of consumer studies, 39(6), pp.692-707.

12. Cho, Y.N., Thyroff, A., Rapert, M.I., Park, S.Y. and Lee, H.J., 2013. To be or not to be green: Exploring individualism and collectivism as antecedents of environmental behaviour. Journal of Business Research, 66(8), pp.1052-1059.

13. da Costa, J.P., Santos, P.S., Duarte, A.C. and Rocha-Santos, T., 2016. (Nano) plastics in the environment-sources, fates and effects. Science of The Total Environment, 566, pp.15-26.

14. Diamantopoulos, A., Siguaw, J. A., and Siguaw, J. A. (2000). Introducing LISREL: A guide for the uninitiated. Sage. Browne, M. W., \& Cudeck, R. (1993). Alternative ways of assessing model fit. Sages focus editions, 154, 136-136.

15. Fornell, C. and Larcker, D.F. (1981), "Evaluating structural equation models with unobservable variables and measurement error", Journal of Marketing Research, Vol. 18 No. 1, pp. 39-50.

16. Fowler III, A.R. and Close, A.G., 2012. It ain't easy being green: Macro, meso, and micro green advertising agendas. Journal of Advertising, 41(4), pp.119-132.

17. Ghosh Chowdhury, T., Micu, C., Ratneshwar, S. and Kim, E.A., 2015. What to Get and What to Give Up: How Different Decision Tasks and Product Types Affect the Persuasiveness of Promotion-versus Prevention-Focused Messages. Psychology \& Marketing, 32(9), pp.920-933. 
18. Grunert, K.G., Lähteenmäki, L., Boztug, Y., Martinsdóttir, E., Ueland, Ø., Åström, A. and Lampila, P., 2009. Perception of health claims among Nordic consumers. Journal of Consumer Policy, 32(3), pp.269-287.

19. Gupta, S. and Ogden, D.T., 2009. To buy or not to buy? A social dilemma perspective on green buying. Journal of Consumer Marketing, 26(6), pp.376-391.

20. Hair, J. F., Black, W. C., Babin, B. J., Anderson, R. E., and Tatham, R. L. (2006), "Multivariate data analysis (Vol. 6), "Upper Saddle River, NJ: Pearson Prentice Hall.

21. Haught, H.M., Rose, J., Geers, A. and Brown, J.A., 2015. Subjective social status and well-being: the role of referent abstraction. The Journal of social psychology, 155(4), pp.356-369.

22. Henseler, J., Ringle, C.M. and Sinkovics, R.R., 2009. The use of partial least squares path modeling in international marketing. In New challenges to international marketing (pp. 277-319). Emerald Group Publishing Limited.

23. Higgins, E.T., 1997. Beyond pleasure and pain. American psychologist, 52(12), p.1280.

24. Higgins, E.T., 2012. Regulatory focus theory. Handbook of theories of social psychology, 1, pp.483-504.

25. Hofstede, G., 1980. Motivation, leadership, and organization: do American theories apply abroad? Organizational dynamics, 9(1), pp.42-63.

26. Hsu, C.L. and Chen, M.C., 2014. Explaining consumer attitudes and purchase intentions toward organic food: Contributions from regulatory fit and consumer characteristics. Food Quality and Preference, 35, pp.6-13.

27. Imam, F., 2013. Individualism-Collectivism as Related to Voting Behavior of Youth and Adults in Pakistan. New Horizons, 7(2), p.1. 
28. Jamal, A. and Sharifuddin, J., 2015. Perceived value and perceived usefulness of halal labeling: The role of religion and culture. Journal of Business Research, 68(5), pp.933941.

29. Kareklas, I., Carlson, J.R. and Muehling, D.D., 2012. The role of regulatory focus and self-view in "green" advertising message framing. Journal of Advertising, 41(4), pp.2539.

30. Kim, U.E., Triandis, H.C., Kâğitçibaşi, Ç.E., Choi, S.C.E. and Yoon, G.E., 1994. Individualism and collectivism: Theory, method, and applications. Sage Publications, Inc.

31. Kim, Y. and Choi, S.M., 2005. Antecedents of green purchase behaviour: An examination of collectivism, environmental concern, and PCE. ACR North American Advances.

32. Kollmuss, A. and Agyeman, J., 2002. Mind the gap: why do people act environmentally and what are the barriers to pro-environmental behavior?. Environmental education research, 8(3), pp.239-260.

33. Komarraju, M. and Cokley, K.O., 2008. Horizontal and vertical dimensions of individualism-collectivism: A comparison of African Americans and European Americans. Cultural Diversity and Ethnic Minority Psychology, 14(4), p.336.

34. Kruglanski, A.W., 2006. The nature of fit and the origins of "feeling right": A goalsystemic perspective. Journal of Marketing Research, 43(1), pp.11-14.

35. Lee, A.Y. and Aaker, J.L., 2004. Bringing the frame into focus: the influence of regulatory fit on processing fluency and persuasion. Journal of personality and social psychology, 86(2), p.205. 
36. Lee, A.Y., Aaker, J.L. and Gardner, W.L., 2000. The pleasures and pains of distinct self-construal: The role of interdependence in regulatory focus. Journal of personality and social psychology, 78(6), p.1122.

37. Lu, L.C., Chang, H.H. and Yu, S.T., 2013. Online shoppers' perceptions of e-retailers' ethics, cultural orientation, and loyalty: an exploratory study in Taiwan. Internet Research, 23(1), pp.47-68.

38. Luomala, H.T., Kumar, R., Singh, J.D. and Jaakkola, M., 2015. When an intercultural business negotiation fails: comparing the emotions and behavioural tendencies of individualistic and collectivistic negotiators. Group Decision and Negotiation, 24(3), pp.537-561.

39. Markus, H.R. and Kitayama, S., 1991. Culture and the self: Implications for cognition, emotion, and motivation. Psychological review, 98(2), p.224.

40. McCarty, J.A. and Shrum, L.J., 2001. The influence of individualism, collectivism, and locus of control on environmental beliefs and behaviour. Journal of Public Policy \& Marketing, 20(1), pp.93-104.

41. Miniero, G., Codini, A., Bonera, M., Corvi, E. and Bertoli, G., 2014. Being green: from attitude to actual consumption. International journal of consumer studies, 38(5), pp.521-528.

42. Moisander, J., 2007. Motivational complexity of green consumerism. International journal of consumer studies, 31(4), pp.404-409.

43. Morren, M. and Grinstein, A., 2016. Explaining environmental behaviour across borders: A meta-analysis. Journal of Environmental Psychology, 47, pp.91-106. 
44. Mostafa, M.M., 2007. Gender differences in Egyptian consumers' green purchase behaviour: the effects of environmental knowledge, concern and attitude. International Journal of Consumer Studies, 31(3), pp.220-229.

45. Nair, S.R. and Little, V.J., 2016. Context, culture and green consumption: a new framework. Journal of International Consumer Marketing, 28(3), pp.169-184.

46. Onwezen, M.C., Bartels, J. and Antonides, G., 2014. The self-regulatory function of anticipated pride and guilt in a sustainable and healthy consumption context. European Journal of Social Psychology, 44(1), pp.53-68.

47. Oreg, S. and Katz-Gerro, T., 2006. Predicting pro-environmental behaviour crossnationally: Values, the theory of planned behaviour, and value-belief-norm theory. Environment and Behavior, 38(4), pp.462-483.

48. Ouschan, L., Boldero, J.M., Kashima, Y., Wakimoto, R. and Kashima, E.S., 2007. Regulatory focus strategies scale: A measure of individual differences in the endorsement of regulatory strategies. Asian Journal of Social Psychology, 10(4), pp.243-257.

49. Oyserman, D., Coon, H.M. and Kemmelmeier, M., 2002. Rethinking individualism and collectivism: Evaluation of theoretical assumptions and meta-analyses. Psychological bulletin, 128(1), p.3.

50. Park, H., Russell, C. and Lee, J., 2007. National culture and environmental sustainability: A cross-national analysis. Journal of Economics and Finance, 31(1), pp.104-121. 
51. Parker, A.G. and Grinter, R.E., 2014. Collectivistic health promotion tools: Accounting for the relationship between culture, food and nutrition. International Journal of Human-Computer Studies, 72(2), pp.185-206.

52. Pentina, I., Bailey, A.A. and Zhang, L., 2018. Exploring effects of source similarity, message valence, and receiver regulatory focus on yelp review persuasiveness and purchase intentions. Journal of Marketing Communications, 24(2), pp.125-145.

53. Price, J.C., Walker, I.A. and Boschetti, F., 2014. Measuring cultural values and beliefs about environment to identify their role in climate change responses. Journal of Environmental Psychology, 37, pp.8-20.

54. Pula, K., Parks, C.D. and Ross, C.F., 2014. Regulatory focus and food choice motives. Prevention orientation associated with mood, convenience, and familiarity. Appetite, 78, pp.15-22.

55. Quazi, A., Amran, A., \& Nejati, M. (2016), “Conceptualizing and measuring consumer social responsibility: a neglected aspect of consumer research", International Journal of Consumer Studies, Vol. 40 No. 1, pp. 48-56.

56. Sandhu, M.S. and Ching, P.W., 2014. Relationship between Individual Cultural Values and Knowledge Sharing in Selected Multinational Companies in Malaysia. International Journal of Business and Economics, 13(1), p.1.

57. Schwartz, S.H., 1992. Universals in the content and structure of values: Theoretical advances and empirical tests in 20 countries. In Advances in experimental social psychology (Vol. 25, pp. 1-65). Academic Press.

58. Shah, J., Higgins, T. and Friedman, R.S., 1998. Performance incentives and means: how regulatory focus influences goal attainment. Journal of personality and social psychology, 74(2), p.285. 
59. Shavitt, S. and Cho, H., 2016. Culture and consumer behaviour: the role of horizontal and vertical cultural factors. Current opinion in psychology, 8, pp.149-154.

60. Shavitt, S., Johnson, T.P. and Zhang, J., 2011. Horizontal and vertical cultural differences in the content of advertising appeals. Journal of international consumer marketing, 23(3-4), pp.297-310.

61. Shavitt, S., Lalwani, A.K., Zhang, J. and Torelli, C.J., 2006. The horizontal/vertical distinction in cross-cultural consumer research. Journal of Consumer Psychology, 16(4), pp.325-342.

62. Shukla, P., Singh, J. and Banerjee, M., 2015. They are not all same: variations in Asian consumers' value perceptions of luxury brands. Marketing Letters, 26(3), pp.265-278.

63. Singelis, T.M., Triandis, H.C., Bhawuk, D.P. and Gelfand, M.J., 1995. Horizontal and vertical dimensions of individualism and collectivism: A theoretical and measurement refinement. Cross-cultural research, 29(3), pp.240-275.

64. Soyez, K., 2012. How national cultural values affect pro-environmental consumer behavior. International Marketing Review, 29(6), pp.623-646.

65. Taras, V., Steel, P. and Kirkman, B.L., 2012. Improving national cultural indices using a longitudinal meta-analysis of Hofstede's dimensions. Journal of World Business, 47(3), pp.329-341.

66. Torelli, C.J., Monga, A.B. and Kaikati, A.M., 2012. Doing poorly by doing good: Corporate social responsibility and brand concepts. Journal of Consumer Research, 38(5), pp.948-963. 
67. Torres, C.V. and Pérez-Nebra, A.R., 2007. The influence of human values on holiday destination choice in Australia and Brazil. BAR-Brazilian Administration Review, 4(3), pp.63-76.

68. Triandis, H.C. and Gelfand, M.J., 1998. Converging measurement of horizontal and vertical individualism and collectivism. Journal of personality and social psychology, 74(1), p.118.

69. Van Lange, P.A., Joireman, J., Parks, C.D. and Van Dijk, E., 2013. The psychology of social dilemmas: A review. Organizational Behaviour and Human Decision Processes, 120(2), pp.125-141.

70. Wang, Y., 2014. Individualism/collectivism, charitable giving, and cause-related marketing: a comparison of Chinese and Americans. International Journal of Nonprofit and Voluntary Sector Marketing, 19(1), pp.40-51.

71. Waylen, K.A., Fischer, A., McGowan, P.J. and Milner-Gulland, E.J., 2012. Interactions between a collectivist culture and Buddhist teachings influence environmental concerns and behaviours in the Republic of Kalmykia, Russia. Society \& Natural Resources, 25(11), pp.1118-1133.

72. Wong, J., Newton, J. D., \& Newton, F. J. (2014). Effects of power and individual-level cultural orientation on preferences for volunteer tourism. Tourism Management, 42, 132-140.

73. Yi-Cheon Yim, M., L. Sauer, P., Williams, J., Lee, S.J. and Macrury, I., 2014. Drivers of attitudes toward luxury brands: A cross-national investigation into the roles of interpersonal influence and brand consciousness. International Marketing Review, 31(4), pp.363-389. 
74. Zagata, L., 2014. Towards conscientious food consumption: exploring the values of Czech organic food consumers. International journal of consumer studies, 38(3), pp.243-250.

75. Zhang, J. and Nelson, M.R., 2016. The effects of vertical individualism on status consumer orientations and behaviours. Psychology \& Marketing, 33(5), pp.318-330. 


\section{Bibliographical statement}

Saleem ur Rahman is a doctoral student at the School of Marketing and Communication, University of Vaasa, Finland. His area of expertise focuses on Consumer psychology, Sustainability, Sustainable consumption, Green marketing and, International marketing. 